\title{
Blood eosinophil count as a prognostic biomarker in COPD
}

This article was published in the following Dove Press journal:

International Journal of COPD

Yeon-Mok Oh, ${ }^{1, *}$ Keu Sung

Lee, ${ }^{2, *}$ Yoonki Hong, ${ }^{3, *}$ Sung Chul

Hwang, ${ }^{2}$ Jae Yeol Kim, ${ }^{4}$ Deog

Keom Kim, ${ }^{5}$ Kwang $\mathrm{Ha} \mathrm{Yoo,}{ }^{6}$

Ji-Hyun Lee, ${ }^{7}$ Tae-Hyung Kim, ${ }^{8}$

Seong Yong Lim, ${ }^{9}$ Chin Kook

Rhee, ${ }^{10}$ Hyoung Kyu Yoon, ${ }^{1}$ Sang

Yeub Lee, ${ }^{12}$ Yong Bum Park, ${ }^{13}$

Jin Hee Jung, ${ }^{14}$ Woo Jin Kim, ${ }^{3}$

Sang-Do Lee,' Joo Hun Park ${ }^{2}$

'Department of Pulmonary and Critical Care

Medicine and Clinical Research Center for Chronic

Obstructive Airway Diseases, Asan Medical Center,

University of Ulsan College of Medicine, Seoul, Korea;

${ }^{2}$ Department of Pulmonary and Critical Care Medicine,

Ajou University School of Medicine, Suwon, Korea;

Health Center, Kangwon National University,

Kangwon National University Hospital, Chuncheon,

Korea; ${ }^{4}$ Department of Internal Medicine, Chung-Ang of Pulmonary and Critical Care Medicine, Department of Internal Medicine, Seoul Metropolitan GovernmentSeoul National University Boramae Medical Center, Seoul National University College of Medicine, Seoul, Korea; ${ }^{6}$ Department of Internal Medicine, Konkuk University School of Medicine, Seoul, Korea; ${ }^{7}$ Department of Internal Medicine, CHA Bundang Medical Center, CHA University, Seongnam, Korea; ${ }^{8}$ Division of Pulmonology, Department of Internal Medicine, Hanyang University College of Medicine, Guri, Korea; 'Division of Pulmonary and Critical Medicine, Seoul, Korea; ${ }^{10}$ Division of Pulmonary, Allergy and Critical Care Medicine, Department of Internal Medicine, Seoul St Mary's Hospital, Catholic University of Korea, Seoul, Korea; "Division of Respiratory and Critical Care Medicine, Department of Internal Medicine, College of Medicine, Korea University Anam Hospital, Seoul, Korea; '2Division of Respiratory and Critical Care Medicine, Department of Internal Medicine, College of Medicine, Korea University Anam Hospital, Seoul, Korea; ${ }^{13}$ Division of Pulmonary, Allergy and Critical Care Medicine, Department of Internal Medicine, Hallym University Kangdong Sacred Heart Hospital, Seoul, Korea; ${ }^{14}$ Department of Biomedical Korea

*These authors contributed equally to this work

Correspondence: Joo Hun Park

Department of Pulmonary and Critical Care Medicine, Ajou University School of Medicine, Worldcup Road 164, San 5, Wonchon-dong, Yeongtong-gu, Suwon, Gyeonggi-do 16499 South Korea

Tel +82312195116

$\mathrm{Fax}+82312195124$
${ }^{3}$ Department of Internal Medicine and Environmental University College of Medicine, Seoul, Korea; ${ }^{5}$ Division Care Medicine, Department of Medicine, Kangbuk Samsung Hospital, Sungkyunkwan University School of Informatics, Ajou University School of Medicine, Suwon,

Email jhpamc@hanmail.net

Background: High blood eosinophil count is a predictive biomarker for response to inhaled corticosteroids in prevention of acute exacerbation of COPD, and low blood eosinophil count is associated with pneumonia risk in COPD patients taking inhaled corticosteroids. However, the prognostic role of blood eosinophil count remains underexplored. Therefore, we investigated the associated factors and mortality based on blood eosinophil count in COPD.

Methods: Patients with COPD were recruited from 16 hospitals of the Korean Obstructive Lung Disease cohort ( $n=395)$ and COPD in Dusty Area cohort $(n=234)$ of Kangwon University Hospital. The two merged cohorts were divided based on blood eosinophil count into three groups: high ( $\geq 5 \%)$, middle $(2 \%-5 \%)$, and low $(<2 \%)$.

Results: The high group had longer six-minute walk distance (high $=445.8 \pm 81.4$, middle $=428.5 \pm 88.0$, and low $=414.7 \pm 86.3 \mathrm{~m})$, higher body mass index $(23.3 \pm 3.1,23.1 \pm 3.1$, and $\left.22.5 \pm 3.2 \mathrm{~kg} / \mathrm{m}^{2}\right)$, lower emphysema index $(18.5 \pm 14.1,22.2 \pm 15.3$, and $23.7 \pm 16.3)$, and higher inspiratory capacity/total lung capacity ratio $(32.6 \pm 7.4,32.4 \pm 9.2$, and $29.9 \% \pm 8.9 \%)(P<0.05)$. The survival period increased with increasing blood eosinophil count (high $=9.52 \pm 0.23$, middle $=8.47 \pm 1.94$, and low $=7.42 \pm 0.27$ years, $P<0.05$ ). Multivariate linear regression analysis revealed that the emphysema index was independently and negatively correlated with blood eosinophil count $(P<0.05)$.

Conclusion: In COPD, the severity of emphysema was independently linked with low blood eosinophil count and the longer survival period was associated with increased blood eosinophil count, though it was not proven in the multivariate analysis.

Keywords: blood eosinophil, COPD, biomarker

\section{Introduction}

Spirometric definition of chronic obstructive pulmonary disease (COPD) demonstrates the feature of airflow limitation, but COPD has many phenotypes with complex underlying pathophysiology. ${ }^{1}$ The forced expiratory volume in 1 second $\left(\mathrm{FEV}_{1}\right)$, which is a marker for disease severity, has been adopted in numerous trials, but it is not useful as a therapeutic marker because it does not reflect disease activity. ${ }^{2}$ Recently, high blood eosinophil count has been recognized as a biomarker for predicting the response to inhaled corticosteroids in prevention of acute exacerbation, and low blood eosinophil count is associated with the risk of pneumonia in COPD patients taking inhaled corticosteroids. ${ }^{3,4}$ However, there is no consensus regarding what criteria of blood eosinophil count should be used for assessing the therapeutic efficacy. Nonetheless, several findings have shown that patients with COPD and elevated circulating eosinophil counts have more exacerbations, that inhaled corticosteroids are beneficial for reducing the occurrence of exacerbations in patients with elevated eosinophil counts, and that the clinical response to inhaled corticosteroids is enhanced with increasing eosinophil count. ${ }^{3,5-7}$ Recent studies suggested that lower level of circulating eosinophil was linked with severe emphysema in COPD. ${ }^{8,9}$ 
Nevertheless, it is unclear whether blood eosinophil is associated with prognosis, mortality, and structural change in stable COPD. Therefore, this study aimed to investigate the prognosis based on mortality and blood eosinophil count and the association between blood eosinophil count and clinical variables, including radiologic and physiologic factors in COPD.

\section{Materials and methods Study subjects}

Patients were enrolled from two different prospective COPD cohort studies in South Korea: the COPD in Dusty Area (CODA) registry (KCT0000552) and the Korean Obstructive Lung Disease (KOLD) cohort.

The inclusion criteria of the patients with COPD for the merged cohort were based on KOLD design as follows: 1 ) age $\geq 40$ years; 2 ) current or former smoker with a smoking history $\geq 10$ pack-years; 3 ) post-bronchodilator ratio of $\mathrm{FEV}_{1}$ to forced vital capacity $(\mathrm{FVC})<0.7$; 4 ) no or minimal abnormality on chest radiography; 5) neither history of asthma nor physician-diagnosed asthma at enrollment; and 6) exclusion of COPD patients with recent exacerbations or pneumonia for 8 weeks before enrollment.

For the merged cohort, we enrolled 395 patients with COPD from the KOLD and 234 patients with COPD from CODA where blood eosinophil count was available and inclusion criteria were met (Table 1).

KOLD is a prospective cohort, which recruited patients with COPD on an outpatient basis from pulmonary clinics in 16 university-affiliated hospitals from three provinces (Seoul, Gyeonggi-do, and Gangwon-do) in Korea between June 2005 and April 2012 (Figure 1). ${ }^{10}$ For this cohort, we followed the patients every 3 months, and the mean follow-up period was

Table I Baseline characteristics of the patients of each cohort

\begin{tabular}{|c|c|c|c|}
\hline Variables & KOLD & CODA & $P$-value \\
\hline Total number & $395(62.8 \%)$ & $234(37.2 \%)$ & \\
\hline Age (years) & $66.9 \pm 7.5$ & $72.7 \pm 7.0$ & $<0.001$ \\
\hline Gender (male) & 385 (97.5\%) & $230(98.3 \%)$ & 0.499 \\
\hline Smoking (pack-years) & $46.8 \pm 26.5$ & $26.3 \pm 22.6$ & $<0.001$ \\
\hline BMI $\left(\mathrm{kg} / \mathrm{m}^{2}\right)$ & $23.1 \pm 3.2$ & $22.7 \pm 3.2$ & 0.202 \\
\hline Dyspnea (mMRC scale) & $1.7 \pm 1.1$ & $1.5 \pm 1.1$ & 0.049 \\
\hline Leukocyte $\left(\times 10^{3} / \mu \mathrm{L}\right)$ & $7.3 \pm 2.0$ & $6.9 \pm 1.8$ & 0.006 \\
\hline Eosinophil count (\%) & $3.7 \pm 3.3$ & $2.8 \pm 3.2$ & 0.001 \\
\hline \multicolumn{4}{|l|}{$\begin{array}{l}\text { Post-bronchodilator } \\
\text { pulmonary function }\end{array}$} \\
\hline FVC (\%) & $83.3 \pm 16.0$ & $96.0 \pm 19.0$ & $<0.001$ \\
\hline $\mathrm{FEV}_{1}(\%)$ & $54.2 \pm 16.1$ & $77.8 \pm 19.4$ & $<0.001$ \\
\hline $\mathrm{FEV}_{\mathrm{l}} / \mathrm{FVC}(\%)$ & $46.8 \pm 11.2$ & $53.3 \pm 8.8$ & $<0.001$ \\
\hline
\end{tabular}

Abbreviations: BMI, body mass index; CODA, COPD in Dusty Area; KOLD, Korean Obstructive Lung Disease; mMRC, modified Medical Research Council.
4.9 \pm 3.1 years. Patients with heart failure, coronary artery disease, tuberculous-destroyed lung, severe bronchiectasis, pneumoconiosis, lung cancer, home oxygen therapy, or pure asthma were excluded on the basis of the judgment of physicians.

The CODA study was a longitudinal observational study conducted on subjects living in dusty areas near cement plants in the Kangwon and Chungbuk provinces of South Korea. The cohort was created to observe the clinical outcomes of patients with COPD living near cement plants in Korea, as previously described. ${ }^{11}$ The CODA cohort recruited COPD patients in Kangwon University Hospital from 2012 until the end of 2015. The patients were recruited from six administrative districts of Korea where cement plants were located. The study design for CODA cohort, including initial questionnaire, spirometry, laboratory test, and radiologic evaluation was made based on KOLD cohort study. CODA study also excluded patients with major comorbidities as in KOLD. CODA cohort followed the patients every 6 months and the mean follow-up period was $2.2 \pm 1.8$ years.

Both cohorts surveyed major events, including acute exacerbation, new diseases, accidents, or deaths, on an outpatient visit every 3 or 6 months, and identified information on major events about those who do not visit by telephone.

\section{Patients and definition of each condition}

This study is a primary ad hoc analysis with the merged cohort. This merged cohort was categorized into three groups based on blood eosinophil count: high group ( $\geq 5 \%$ ), middle group $(2 \%-5 \%)$, and low group $(<2 \%)$. Acute exacerbation was graded from mild to severe as previously reported during the 1-year follow-up period after enrollment, and only moderate and severe exacerbations were included in the exacerbation group. ${ }^{12}$ Frequent exacerbators were determined as previously defined. ${ }^{1,12}$

This study was approved by the institutional review board of the Asan Medical Center (Approval No 2005-0345), Kangwon University Hospital (IRB No 2012-06-007), and the other participating hospitals. Written informed consent was obtained from all patients.

\section{Methods}

\section{Clinical and physiological measurements}

Baseline information of the study population, including demographic and clinical data, such as age, sex, smoking status, history of exacerbations, and pulmonary function tests, were collected at enrollment. Blood samples, collected at enrollment when the patients were stable, were used for laboratory tests. The body mass index (BMI) was calculated as the 


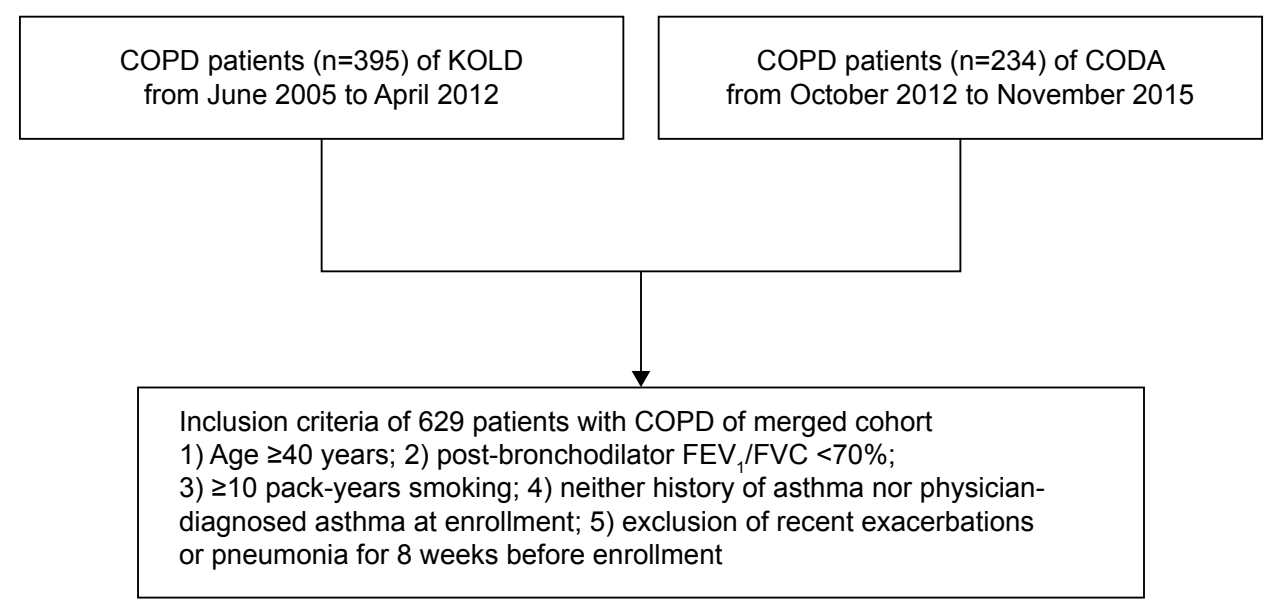

Figure I Flow diagram illustrating patient enrollment.

Abbreviations: CODA, COPD in Dusty Area; KOLD, Korean Obstructive Lung Disease.

body weight divided by the height squared $\left(\mathrm{kg} / \mathrm{m}^{2}\right)$. Dyspnea was assessed using the modified Medical Research Council (mMRC) dyspnea scale and the health-related quality of life was assessed using the St George Respiratory Questionnaire. The six-minute walk test was performed according to the American Thoracic Society statement. ${ }^{13}$

Spirometry was conducted using Vmax 22 (SensorMedics, Yorba Linda, CA, USA) and PFDX (MedGraphics, St. Paul, MN, USA) according to the American Thoracic Society guidelines. ${ }^{14}$ The spirometry reference values were based on the Korean equation. ${ }^{15}$ Post-bronchodilator spirometry values were measured 15 minutes after administering $400 \mu \mathrm{g}$ of salbutamol. Lung volumes, including the total lung capacity (TLC) and residual volume, were measured using body plethysmography by employing V6200 (CareFusion, San Diego, CA, USA), PFDX, or Vmax 22. ${ }^{16}$ The diffusing capacity of carbon monoxide $\left(\mathrm{D}_{\mathrm{LCO}}\right)$ was measured by assessing the single-breath carbon monoxide uptake (Vmax 22 or PFDX). ${ }^{17}$ St George Respiratory Questionnaire, lung volume measurement, $\mathrm{D}_{\mathrm{LCO}}$, and the data of six-minute walk test were collected only in the KOLD cohort.

\section{Chest CT indices for COPD assessment}

Radiological evaluation was performed only in the KOLD cohort. The emphysema index, CT air-trapping index, and airway dimensions were determined from chest CT data, as previously reported. ${ }^{18,19}$ Patients underwent volumetric CT scans at full inspiration and expiration for measuring these indices by using one of three 16-multidetector CT scanners (Somatom Sensation 16, Siemens Medical Solutions, Forchheim, Germany; GE Lightspeed Ultra, General Electric Healthcare, Milwaukee, WI, USA; or Philips Brilliance 16, Philips Medical Systems, Best, the Netherlands).

\section{Analysis}

All data were analyzed using IBM SPSS Statistics for Windows/Macintosh, Version 21.0 (IBM Corporation, Armonk, NY, USA). All values, except for the survival period described as means \pm standard error, were expressed as means \pm standard deviation. A $P$-value $<0.05$ was deemed statistically significant.

Chi-squared test or Fisher's exact test was performed for categorical data.

Distribution of data normality was examined by Kolmogorov-Smirnov test.

For continuous data, one-way analysis of variance was done for data with normal distribution and Kruskal-Wallis test was done for data not showing normal distribution.

A Kaplan-Meier analysis with a log-rank test was performed to evaluate survival. A Cox proportional hazards regression analysis was conducted to identify significant variables associated with survival. Univariate and multivariate linear regression analyses were performed to identify significant variables associated with blood eosinophil count. The demographic variables indicating the sample profile information, including age and sex, and clinically meaningful variables were all included in the multivariate linear regression analysis. To avoid multicollinearity, the variables were included in multiple regression analyses when the variance inflation factor was $<10$.

\section{Results}

\section{Baseline characteristics}

The baseline characteristics of each cohort are shown in Table 1, and the baseline demographics of the two merged cohorts based on blood eosinophil count are shown in Tables 2 and 3. Compared with the middle or low eosinophil 
Table 2 Baseline characteristics of the patients with COPD according to blood eosinophil count

\begin{tabular}{|c|c|c|c|c|}
\hline Variables & $\begin{array}{l}\text { High eosinophil group } \\
\text { (blood eosinophil } \geq 5 \% \text { ) }\end{array}$ & $\begin{array}{l}\text { Middle eosinophil group } \\
\text { (blood eosinophil 2\%-5\%) }\end{array}$ & $\begin{array}{l}\text { Low eosinophil group } \\
\text { (blood eosinophil }<2 \% \text { ) }\end{array}$ & $P$-value \\
\hline Total number & 123 & 301 & 205 & \\
\hline Eosinophil count (\%) & $8.1 \pm 4.6$ & $3.0 \pm 0.8$ & $1.0 \pm 0.5$ & $<0.001$ \\
\hline Age (years) & $69.1 \pm 8.5$ & $68.4 \pm 7.8$ & $69.92 \pm 7.3$ & 0.100 \\
\hline Gender (male) & $98.4 \%(12 I / I 23)$ & $97.7 \%(294 / 30 I)$ & $97.6 \%(200 / 205)$ & 0.665 \\
\hline Current smoker vs former smoker & $46.3 \%$ & $39.2 \%$ & $37.1 \%$ & 0.238 \\
\hline BMI $\left(\mathrm{kg} / \mathrm{m}^{2}\right)$ & $23.3 \pm 3.1$ & $23.1 \pm 3.1$ & $22.5 \pm 3.2$ & 0.042 \\
\hline SGRQ & $33.7 \pm 17.0$ & $31.1 \pm 17.5$ & $34.6 \pm 18.7$ & 0.225 \\
\hline Dyspnea (mMRC scale) & $1.74 \pm 1.07$ & $1.45 \pm 1.10$ & $1.69 \pm 1.10$ & 0.010 \\
\hline \multicolumn{5}{|l|}{ Serum laboratory finding } \\
\hline Leukocyte $\left(\times 10^{3} / \mu \mathrm{L}\right)$ & $7.0 \pm 2.0$ & $6.8 \pm 1.7$ & $7.4 \pm 2.2$ & 0.003 \\
\hline hs-CRP (mg/dL) & $1.02 \pm 0.13$ & $1.01 \pm 0.09$ & $1.02 \pm 0.14$ & 0.670 \\
\hline Hemoglobin (g/dL) & $14.8 \pm 1.3$ & $14.8 \pm 1.4$ & $\mid 4.8 \pm 1.4$ & 0.909 \\
\hline Platelet $\left(\times 10^{3} / \mu \mathrm{L}\right)$ & $236.7 \pm 63.1$ & $234.3 \pm 59.2$ & $240.2 \pm 65.2$ & 0.725 \\
\hline Protein $(\mathrm{g} / \mathrm{dL})$ & $7.06 \pm 0.52$ & $7.10 \pm 0.47$ & $7.03 \pm 0.52$ & 0.486 \\
\hline Albumin (g/dL) & $4.13 \pm 0.36$ & $4.19 \pm 0.34$ & $4 .|8 \pm 0.3|$ & 0.249 \\
\hline Cholesterol (mg/dL) & $182.5 \pm 36.5$ & $180.3 \pm 36.9$ & $182.3 \pm 37.5$ & 0.831 \\
\hline Creatinine (mg/dL) & $1.03 \pm 0.22$ & $0.99 \pm 0.38$ & $0.93 \pm 0.21$ & 0.009 \\
\hline
\end{tabular}

Abbreviations: BMI, body mass index; SGRQ, St George Respiratory Questionnaire; hs-CRP, high-sensitivity C-reactive protein; mMRC, modified Medical Research Council; SGRQ, St George Respiratory Questionnaire.

groups, the high blood eosinophil group had higher BMI (high group $=23.3 \pm 3.1$, middle group $=23.1 \pm 3.1$, and lower group $\left.=22.5 \pm 3.2 \mathrm{~kg} / \mathrm{m}^{2} ; P=0.042\right)$, longer six-minute walk distance (6MWD) (high group $=445.8 \pm 81.4 \mathrm{~m}$, middle group $=428.5 \pm 88.0 \mathrm{~m}$, and lower group $=414.7 \pm 86.3 \mathrm{~m}$; $P=0.029$ ), lower emphysema index (high group $=18.5 \pm 14.1$, middle group $=22.2 \pm 15.3$, and lower group $=23.7 \pm 16.3$; $P=0.077$ ), higher $\mathrm{D}_{\mathrm{LCO}}$ (high group $=82.4 \pm 21.9$, middle group $=74.3 \pm 23.7$, and lower group $=76.8 \pm 24.5 ; P=0.035$ ), and higher inspiratory capacity/TLC ratio (high group $=32.6 \pm 7.4$, middle group $=32.4 \pm 9.2$, and lower group $=29.9 \% \pm 8.9 \% ; P=0.036$ ).

Table 3 Physiological and radiological findings of patients with COPD according to blood eosinophil count

\begin{tabular}{|c|c|c|c|c|}
\hline Variables & $\begin{array}{l}\text { High eosinophil group } \\
\text { (blood eosinophil } \geq 5 \% \text { ) }\end{array}$ & $\begin{array}{l}\text { Middle eosinophil group } \\
\text { (blood eosinophil 2\%-5\%) }\end{array}$ & $\begin{array}{l}\text { Low eosinophil group } \\
\text { (blood eosinophil < } 2 \% \text { ) }\end{array}$ & $P$-value \\
\hline \multicolumn{5}{|l|}{$\begin{array}{l}\text { Post-bronchodilator } \\
\text { pulmonary function }\end{array}$} \\
\hline FVC (\%) & $85.1 \pm 16.5$ & $89.2 \pm 17.4$ & $88.0 \pm 19.7$ & 0.542 \\
\hline $\mathrm{FEV}_{1}(\%)$ & $62.4 \pm 19.4$ & $63.8 \pm 19.6$ & $62.1 \pm 23.2$ & 0.625 \\
\hline $\mathrm{FEV}_{\mathrm{I}} / \mathrm{FVC}(\%)$ & $52.3 \pm 11.4$ & $51.5 \pm 11.6$ & $49.7 \pm 11.2$ & 0.108 \\
\hline $\mathrm{D}_{\mathrm{LCO}}$ & $82.4 \pm 21.9(83)$ & $74.3 \pm 23.7(163)$ & $76.8 \pm 24.5(118)$ & 0.035 \\
\hline $\mathrm{D}_{\mathrm{LCO}} / \mathrm{VA}$ & $84.6 \pm 23.7(8 \mathrm{I})$ & $76.1 \pm 22.6(\mid 6 I)$ & $76.3 \pm 25.2(115)$ & 0.023 \\
\hline RV/TLC (\%) & $45.2 \pm 12.8(81)$ & $44.2 \pm 12.3(167)$ & $47.7 \pm 13.6(118)$ & 0.074 \\
\hline IC/TLC (\%) & $32.6 \pm 7.4(79)$ & $32.4 \pm 9.2(158)$ & $29.9 \pm 8.9(112)$ & 0.036 \\
\hline \multicolumn{5}{|l|}{ Six-minute walk test } \\
\hline 6MWD (m) & $445.8 \pm 8 I .4(84)$ & $428.5 \pm 88.0(177)$ & $4 \mid 4.7 \pm 86.3(|| 9)$ & 0.029 \\
\hline Resting $\mathrm{O}_{2}$ Sat (\%) & $96.7 \pm 1.7(84)$ & $96.4 \pm 1.8(175)$ & $96.4 \pm 1.7$ (119) & 0.404 \\
\hline Minimum $\mathrm{O}_{2}$ Sat (\%) & $95.3 \pm 4.4(84)$ & $94.4 \pm 5.3(174)$ & $94.9 \pm 3.8(119)$ & 0.338 \\
\hline \multicolumn{5}{|l|}{ Radiological findings } \\
\hline Emphysema index & 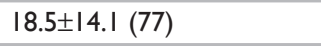 & $22.2 \pm 15.3(155)$ & $23.7 \pm 16.3(106)$ & 0.077 \\
\hline Wall area (\%) & $66.8 \pm 5.4(77)$ & $66.2 \pm 4.8(155)$ & $66.7 \pm 5.0(106)$ & 0.679 \\
\hline Air-trapping index & $0.94 \pm 0.04(75)$ & $0.95 \pm 0.04(152)$ & $0.95 \pm 0.04(104)$ & 0.330 \\
\hline Frequent exacerbators & $13.9 \%$ & $14.0 \%$ & $20.1 \%$ & 0.176 \\
\hline
\end{tabular}

Notes: The number of patients is noted within parenthesis if any of the values for an item are missing. Wall area\% $=$ wall area/(wall area + lumen area) $\times 100$.

Abbreviations: $\mathrm{D}_{\mathrm{LCO}} / \mathrm{VA}$, diffusing capacity for carbon monoxide/alveolar volume; IC, inspiratory capacity; $\mathrm{O}_{2}$ Sat, oxygen saturation; RV, residual vol; $6 \mathrm{MWD}$, six minute walk distance; TLC, total lung capacity. 


\section{Factors associated with blood eosinophil count}

Univariate linear regression analysis demonstrated that $\mathrm{D}_{\mathrm{LCO}}$ $(\mathrm{B}=0.017, P=0.016)$ and emphysema index $(\mathrm{B}=-0.034$, $P=0.006)$ were associated with blood eosinophil count (Table 4). Six-minute walk distance $(\mathrm{B}=0.009, P=0.061)$ tended to be associated with blood eosinophil count (Table 4). In multivariate stepwise linear regression analysis, the emphysema index showed an independent negative correlation with blood eosinophil count ( $\mathrm{B}=-0.034, P=0.008$ ) (Table 4).

\section{Survival analyses}

Of the 58 patients with COPD in the KOLD cohort who died during the observation period, death was most frequently due to pneumonia (six patients), respiratory failure (six patients), acute exacerbation of COPD (six patients), lung cancer (six patients), and other cancers (nine patients). Other causes were myocardial infarction (three patients), respiratory failure after surgery (two patients), septic shock (two patients), pneumothorax (one patient), liver cirrhosis (one patient), multiorgan failure (one patient), and suicide (one patient). Of the 10 patients with COPD in the CODA cohort who died during the observation period, death was due to pneumonia (three patients), respiratory failure (two patients), multiorgan failure (one patient), and gastric cancer (one patient). Since the cause of death was unidentified in $24.1 \%(14 / 58)$ of the instances in the KOLD cohort and 30\% (3/10) in the CODA cohort, only all-cause mortality was used for the survival analyses.

A Kaplan-Meier analysis showed that the survival period increased with an increase in blood eosinophil count (high group $=9.52 \pm 0.23$ years, middle group $=8.47 \pm 1.94$ years, and low group $=7.42 \pm 0.27$ years; $P<0.001$ ) (Figure 2 ).

The univariate Cox analysis showed that age $(\mathrm{HR}=1.124$, $95 \% \mathrm{CI}=1.078-1.171, P<0.001)$, female sex $(\mathrm{HR}=0.542$, 95\% CI $=0.075-3.919, P=0.544)$, blood eosinophil count $(\mathrm{HR}=0.872,95 \% \mathrm{CI}=0.777-0.979, P=0.020), \mathrm{BMI}$ $(\mathrm{HR}=0.758,95 \% \mathrm{CI}=0.698-0.823, P<0.001)$, dyspnea scale by $\mathrm{mMRC}(\mathrm{HR}=1.918,95 \% \mathrm{CI}=1.506-2.442$, $P<0.001)$, post-bronchodilator $\mathrm{FEV}_{1}(\mathrm{HR}=0.956,95 \%$

Table 4 Factors associated with blood eosinophil count according to linear regression method

\begin{tabular}{|c|c|c|c|c|}
\hline Variables & B & SE & $\boldsymbol{t}$ & $P$-value \\
\hline Univariate analysis & & & & \\
\hline $\begin{array}{l}\text { Age (years) } \\
\text { R-square }=0.002 \text {, adjusted R-square }=0.00 \mathrm{I} \text {, } \\
F=1.284, P \text {-value }=0.258\end{array}$ & -0.019 & 0.017 & -1.133 & 0.258 \\
\hline $\begin{array}{l}\text { Gender (male) } \\
\text { R-square }=0.00 \mathrm{I} \text {, adjusted R-square }=-0.00 \mathrm{I} \text {, } \\
F=0.139, P \text {-value }=0.7 \mathrm{I} 0\end{array}$ & -0.333 & 0.894 & -0.372 & 0.710 \\
\hline $\begin{array}{l}\text { Leukocyte }\left(\times 10^{3} / \mu \mathrm{L}\right) \\
\quad \text {-square }=0.00 \mathrm{I} \text {, adjusted R-square }=-0.00 \mathrm{I} \text {, } \\
F=0.286, P \text {-value }=0.593\end{array}$ & 0.036 & 0.067 & 0.535 & 0.593 \\
\hline $\begin{array}{l}\text { BMI }\left(\mathrm{kg} / \mathrm{m}^{2}\right) \\
\text { R-square }=0.002 \text {, adjusted R-square }=0.00 \mathrm{I} \text {, } \\
F=\mathrm{I} . \mathrm{I} 23, P \text {-value }=0.290\end{array}$ & 0.044 & 0.041 & 1.060 & 0.290 \\
\hline $\begin{array}{l}\text { IC } / \text { TLC }(\%) \\
\quad \text {-square }=0.002 \text {, adjusted R-square }=-0.001 \text {, } \\
F=0.583, P \text {-value }=0.446\end{array}$ & 0.015 & 0.020 & 0.764 & 0.446 \\
\hline $\begin{array}{l}D_{\text {LCO }}(\%) \\
\quad \text { R-square }=0.015 \text {, adjusted R-square }=0.012 \text {, } \\
\quad F=5.827, P \text {-value }=0.016\end{array}$ & 0.017 & 0.007 & 2.414 & 0.016 \\
\hline $\begin{array}{l}\text { Emphysema index } \\
\qquad \text {-square }=0.023 \text {, adjusted R-square }=0.020 \text {, } \\
F=7.75 \mathrm{I}, P \text {-value }=0.006\end{array}$ & -0.034 & 0.012 & -2.784 & 0.006 \\
\hline $\begin{array}{l}\text { 6MWD }(\mathrm{m}) \\
\quad \mathrm{R} \text {-square }=0.009, \text { adjusted R-square }=0.007 \\
F=3.544, P \text {-value }=0.06 \mathrm{I}\end{array}$ & 0.009 & 0.002 & 1.882 & 0.061 \\
\hline $\begin{array}{l}\text { aultivariate analysis by stepwise method } \\
\text { Emphysema index }\end{array}$ & -0.034 & 0.013 & -2.689 & 0.008 \\
\hline
\end{tabular}

Note: aAdjustment for age, gender, BMI, 6MWD, $\mathrm{D}_{\mathrm{LCO}}$, and emphysema index.

Abbreviations: BMI, body mass index; $\mathrm{D}_{\text {LCO }}$, diffusing capacity for carbon monoxide; IC, inspiratory capacity; SE, standard error; 6MWD, six minute walk distance; TLC, total lung capacity. 


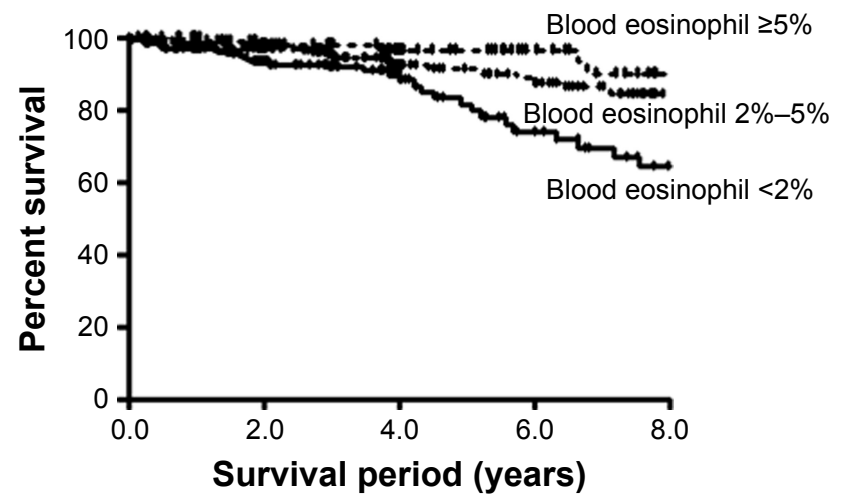

Figure 2 Survival analysis in the high eosinophil group (mean survival $=9.52 \pm 0.23$ years), middle group (mean survival $=8.47 \pm 1.94$ years), and low group (mean survival $=7.42 \pm 0.27$ years $)(P<0.00 \mathrm{I})$ by using the Kaplan-Meier method.

$\mathrm{CI}=0.940-0.972, P<0.001)$, and 6MWD $(\mathrm{HR}=0.991$, 95\% CI $=0.988-0.994, P<0.001)$ were significant factors associated with survival. The multivariate Cox regression analysis showed that high blood eosinophil count was an independent risk factor for improved survival $(\mathrm{HR}=0.897$, 95\% CI $=0.802-0.996, P=0.041)$ in model 1 adjusted for age and sex, but not in model 2 adjusted for BMI, postbronchodilator $\mathrm{FEV}_{1}$, and dyspnea scale by mMRC, along with age and sex (Table 5).

\section{Discussion}

The aim of our study was to evaluate the utility of blood eosinophil count as a biomarker by investigating the mortality based on blood eosinophil count and identify factors that are independently associated with blood eosinophil count in COPD. Our data suggested that, in COPD, the survival period increased according to the blood eosinophil count, and that the emphysema index had an independent and inverse association with blood eosinophil count.

Our study revealed a few interesting findings. First, our data demonstrated that the severity of radiologic emphysema had an independent association with low blood eosinophil count in the multivariate linear regression analysis. The association between blood eosinophil count and structural changes in the COPD lung, such as emphysema, has not yet been well studied. A previous paper by Nishmura et al reporting that those with rapid decline in lung function displayed more severe emphysema and lower levels of circulating eosinophils was indirectly suggestive of a possible association between emphysema and blood eosinophil count in COPD. ${ }^{8}$

Recently, Papaioannou et al's study, including 98 patients with COPD reported that patients with significant emphysema defined by emphysematous lesions in $\geq 15 \%$ of the pulmonary parenchyma had lower blood eosinophil counts compared with patients without emphysema. ${ }^{9}$ However, an independent association between blood eosinophil count and the radiologic emphysema index found in our study has not been reported yet in a big cohort.

The emphysematous phenotype is usually characterized by poor outcomes in COPD, such as lower BMI, impaired quality of life, rapid lung function decline, the development of pneumonia, and frequent exacerbations., ${ }^{3,20-24}$ Therefore, the higher blood eosinophil count in COPD patients with less emphysematous lesion in our study could explain the better prognosis of the high blood eosinophil group. This is also supported by our finding of longer survival periods in patients with COPD having higher eosinophil counts.

The beneficial role of inhaled corticosteroids in the high eosinophil group appears to be partly explained by our finding that this group has fewer emphysematous features that would respond well to pharmacological intervention. Previous studies have reported that, in the high eosinophil group of COPD, acute exacerbation is better prevented or treated using inhaled corticosteroids. ${ }^{4,7}$ Studies analyzing the KOLD data also showed that the emphysematous phenotype in COPD does not respond to pharmacological interventions, including inhaled corticosteroids and long-acting beta agonists, and high blood eosinophil count can be a possible biomarker

Table 5 Prognostic factors for mortality in the total COPD group according to multivariate Cox regression analysis

\begin{tabular}{|c|c|c|c|c|}
\hline \multirow[t]{2}{*}{ Variables } & \multicolumn{2}{|l|}{ Model I } & \multicolumn{2}{|l|}{ Model 2} \\
\hline & HR (95\% CI) & $P$-value & HR $(95 \% \mathrm{Cl})$ & $P$-value \\
\hline Age (years) & $1.122(1.076-1.169)$ & $<0.001$ & $1.102(1.054-1.153)$ & $<0.001$ \\
\hline Gender (female) & $0.44 I(0.06 I-3.188)$ & 0.417 & $0.919(0.123-6.875)$ & 0.934 \\
\hline Blood eosinophil count (\%) & $0.897(0.802-0.996)$ & 0.041 & $0.922(0.839-1.013)$ & 0.091 \\
\hline Dyspnea (mMRC scale) & & & $1.459(1.119-1.904)$ & 0.005 \\
\hline BMI $\left(\mathrm{kg} / \mathrm{m}^{2}\right)$ & & & $0.827(0.757-0.904)$ & $<0.001$ \\
\hline Post-BD FEV $(\%)$ & & & $0.976(0.959-0.994)$ & 0.008 \\
\hline
\end{tabular}

Abbreviations: BMI, body mass index; HR, Hazard ratio; mMRC, modified Medical Research Council; Post-BD FEV , post-bronchodilator FEV . 
for the identification of patients with COPD who would show a favorable $\mathrm{FEV}_{1}$ improvement in response to inhaled corticosteroid/long-acting beta-agonist treatment. ${ }^{25-27}$

Second, a longer survival period was associated with a higher blood eosinophil count in the Kaplan-Meier analysis. However, further validation in a bigger cohort is deemed necessary, since this association was not proven in the multivariate Cox regression analysis.

Our cohorts were trisected in the Kaplan-Meier analysis on the basis of blood eosinophil counts of 5\% (which is the upper normal value of blood eosinophil count) and $2 \%$ (which is the value that has been prospectively identified and studied at the time of an exacerbation). ${ }^{3,6,28}$ Some studies have suggested $4 \%$ or even $6 \%$ as the best threshold. ${ }^{29}$ This study measured the blood eosinophil count at the initial visit when the patients were stable. Moreover, all patients with asthma were excluded from our COPD groups to rule out the influence of asthma on blood eosinophil count.

Our findings are supported by Casanova's study, which showed that in patients with COPD, blood eosinophil count $\geq 300$ cells $/ \mu \mathrm{L}$ persisting $>2$ years was not a risk factor for COPD exacerbations, but a high eosinophil count was associated with better survival. ${ }^{30}$ This study also evaluated the impact of persistent blood eosinophilia on COPD, considering the fluctuating nature of blood eosinophil count and many factors affecting blood eosinophils, including the coexistence of asthma, viral infection, parasitic infection, or medication..$^{30}$ Another ongoing study is evaluating the impact of persistent blood eosinophilia on COPD in the KOLD cohort. However, a contradicting report suggested that, regardless of the eosinophilic cutoff, patients with eosinophilic COPD exhibited no specific characteristic in terms of symptoms, lung function, exacerbation rate, and prognosis, thereby suggesting that the association of higher eosinophil count with exacerbations reported in previous studies could be population-specific and does not support generalizing the use of eosinophil count as a biomarker for COPD phenotyping. ${ }^{31}$

This study also has a few limitations. First, some variables were analyzed only in a single cohort because the two cohorts were not exactly matched in terms of their measured parameters. Second, our study included only Asian COPD outpatients with no or few comorbidities; therefore, the results cannot be generalized to the entire COPD population and further validation seems necessary to generalize our findings. Third, this study cannot explain the causal link between emphysema and eosinophil count. Fourth, the COPD assessment test score was not analyzed because it was not obtained at the initial enrolment. Fifth, the history of therapeutic intervention was not considered in our analysis since this study was not designed as a randomized controlled trial. Sixth, sputum eosinophil count was not obtained in our study.

\section{Conclusion}

Our data suggest that in COPD, the severity of emphysema was independently associated with low blood eosinophil count and the longer survival period was linked with high blood eosinophil count, though it was not proven in the multivariate analysis.

\section{Acknowledgments}

This research is supported by a grant from the Korea Healthcare Technology R\&D Project, Ministry for Health and Welfare, Republic of Korea (grant number A102065 and HI16C0992) and a grant from the Ministry of Environment, Republic of Korea (Environmental Health Center of Kangwon National University Hospital).

\section{Disclosure}

CK Rhee reports personal fees from MSD Korea, AstraZeneca, Novartis, Mundipharma, and Boehringer Ingelheim, outside the submitted work. Y-M Oh received payment for lecturing from MSD Korea, AstraZeneca Korea, Boehringer Ingelheim Korea, Novartis, DongWha, Takeda, and GSK Korea. S-D Lee received support from Takeda Pharmaceuticals International GmbH for travel to an investigator meeting. He received payment from Takeda Pharmaceuticals International GmbH for attendance at an advisory board. He also received honoraria from GlaxoSmithKline, AstraZeneca, and Boehringer Ingelheim. The authors report no other conflicts of interest in this work.

\section{References}

1. Rabe KF, Hurd S, Anzueto A, et al; Global Initiative for Chronic Obstructive Lung Disease. Global strategy for the diagnosis, management, and prevention of chronic obstructive pulmonary disease: GOLD executive summary. Am J Respir Crit Care Med. 2007;176(6):532-555.

2. Vogelmeier CF, Criner GJ, Martinez FJ, et al. Global Strategy for the Diagnosis, Management, and Prevention of Chronic Obstructive Lung Disease 2017 Report. GOLD Executive Summary. Am J Respir Crit Care Med. 2017;195(5):557-582.

3. Pavord ID, Lettis S, Anzueto A, Barnes N. Blood eosinophil count and pneumonia risk in patients with chronic obstructive pulmonary disease: a patient-level meta-analysis. Lancet Respir Med. 2016;4(9):731-741.

4. Pavord ID, Lettis S, Locantore N, et al. Blood eosinophils and inhaled corticosteroid/long-acting $\beta$-2 agonist efficacy in COPD. Thorax. 2016; 71(2):118-125. 
5. Bafadhel M, Davies L, Calverley PM, Aaron SD, Brightling CE, Pavord ID. Blood eosinophil guided prednisolone therapy for exacerbations of COPD: a further analysis. Eur Respir J. 2014;44(3):789-791.

6. Kerkhof M, Sonnappa S, Postma DS, et al. Blood eosinophil count and exacerbation risk in patients with COPD. Eur Respir J. 2017;50(1): pii:1700761.

7. Pavord ID, Agusti A. Blood eosinophil count: a biomarker of an important treatable trait in patients with airway disease. Eur Respir J. 2016; 47(5):1299-1303.

8. Nishimura M, Makita H, Nagai K, et al; Hokkaido COPD Cohort Study Investigators. Annual change in pulmonary function and clinical phenotype in chronic obstructive pulmonary disease. Am J Respir Crit Care Med. 2012;185(1):44-52.

9. Papaioannou AI, Kostikas K, Papaporfyriou A, et al. Emphysematous phenotype is characterized by low blood Eosinophils: A Cross-Sectional Study. COPD. 2017;14(6):635-640.

10. Oh YM, Park JH, Kim EK, et al. Anemia as a clinical marker of stable chronic obstructive pulmonary disease in the Korean obstructive lung disease cohort. J Thorac Dis. 2017;9(12):5008-5016.

11. Lee $\mathrm{H}$, Hong $\mathrm{Y}$, Lim MN, et al. Inflammatory biomarkers and radiologic measurements in never-smokers with COPD: a cross-sectional study from the CODA cohort. Chron Respir Dis. 2018;15(2):138-145.

12. Oh YM, Sheen SS, Park JH, et al. Emphysematous phenotype is an independent predictor for frequent exacerbation of COPD. Int J Tuberc Lung Dis. 2014;18(12):1407-1414.

13. ATS Committee on Proficiency Standards for Clinical Pulmonary Function Laboratories. ATS statement: guidelines for the six-minute walk test. Am J Respir Crit Care Med. 2002;166(1):111-117.

14. Miller MR, Hankinson J, Brusasco V, et al; ATS/ERS Task Force. Standardisation of spirometry. Eur Respir J. 2005;26(2):319-338.

15. Hwang YI, Kim CH, Kang HR, et al. Comparison of the prevalence of chronic obstructive pulmonary disease diagnosed by lower limit of normal and fixed ratio criteria. J Korean Med Sci. 2009;24(4):621-626.

16. Wanger J, Clausen JL, Coates A, et al. Standardisation of the measurement of lung volumes. Eur Respir J. 2005;26(3):511-522.

17. Macintyre N, Crapo RO, Viegi G, et al. Standardisation of the singlebreath determination of carbon monoxide uptake in the lung. Eur Respir J. 2005;26(4):720-735.

18. Nakano Y, Muro S, Sakai H, et al. Computed tomographic measurements of airway dimensions and emphysema in smokers. Correlation with lung function. Am J Respir Crit Care Med. 2000;162(3 Pt 1): $1102-1108$.

19. Lee YK, Oh YM, Lee JH, et al. Quantitative assessment of emphysema, air trapping, and airway thickening on computed tomography. Lung. 2008;186(3):157-165.
20. Vestbo J, Edwards LD, Scanlon PD, et al; ECLIPSE Investigators. Changes in forced expiratory volume in 1 second over time in COPD. N Engl J Med. 2011;365(13):1184-1192.

21. Hong Y, Lee JS, Yoo KH, et al. Implications of emphysema and lung function for the development of pneumonia in patients with chronic obstructive pulmonary disease. Tuberc Respir Dis (Seoul). 2016;79(2):91-97.

22. Naito K, Yamasaki K, Yatera K, et al. Bacteriological incidence in pneumonia patients with pulmonary emphysema: a bacterial floral analysis using the $16 \mathrm{~S}$ ribosomal RNA gene in bronchoalveolar lavage fluid. Int J Chron Obstruct Pulmon Dis. 2017;12:2111-2120.

23. Makita H, Nasuhara Y, Nagai K, et al; Hokkaido COPD Cohort Study Group. Characterisation of phenotypes based on severity of emphysema in chronic obstructive pulmonary disease. Thorax. 2007; 62(11):932-937.

24. Gietema HA, Edwards LD, Coxson HO, Bakke PS; ECLIPSE Investigators. Impact of emphysema and airway wall thickness on quality of life in smoking-related COPD. Respir Med. 2013;107(8):1201-1209.

25. Lee JH, Lee YK, Kim EK, et al. Responses to inhaled long-acting betaagonist and corticosteroid according to COPD subtype. Respir Med. 2010;104(4):542-549.

26. Park HY, Lee H, Koh WJ, et al; KOLD Study Group. Association of blood eosinophils and plasma periostin with FEV1 response after 3-month inhaled corticosteroid and long-acting beta2-agonist treatment in stable COPD patients. Int J Chron Obstruct Pulmon Dis. 2016;11:23-30.

27. Lee JS, Huh JW, Chae EJ, et al. Predictors of pulmonary function response to treatment with salmeterol/fluticasone in patients with chronic obstructive pulmonary disease. J Korean Med Sci. 2011;26(3): 379-385.

28. Contoli M, Pauletti A, Rossi MR, et al. Long-term effects of inhaled corticosteroids on sputum bacterial and viral loads in COPD. Eur Respir J. 2017;50(4):1700451

29. Pascoe S, Locantore N, Dransfield MT, Barnes NC, Pavord ID. Blood eosinophil counts, exacerbations, and response to the addition of inhaled fluticasone furoate to vilanterol in patients with chronic obstructive pulmonary disease: a secondary analysis of data from two parallel randomised controlled trials. Lancet Respir Med. 2015;3(6): 435-442.

30. Casanova C, Celli BR, de-Torres JP, et al. Prevalence of persistent blood eosinophilia: relation to outcomes in patients with COPD. Eur Respir J. 2017;50(5):1701162.

31. Zysman M, Deslee G, Caillaud D, et al. Relationship between blood eosinophils, clinical characteristics, and mortality in patients with COPD. Int J Chron Obstruct Pulmon Dis. 2017;12:1819-1824.
International Journal of COPD

\section{Publish your work in this journal}

The International Journal of COPD is an international, peer-reviewed journal of therapeutics and pharmacology focusing on concise rapid reporting of clinical studies and reviews in COPD. Special focus is given to the pathophysiological processes underlying the disease, intervention programs, patient focused education, and self management protocols.
Dovepress

This journal is indexed on PubMed Central, MedLine and CAS. The manuscript management system is completely online and includes a very quick and fair peer-review system, which is all easy to use. Visit http://www.dovepress.com/testimonials.php to read real quotes from published authors. 